Filol. Linguíst. Port., São Paulo, v. 16, n. spe, p. 7-10, dez. 2014

http://dx.doi.org/10.11606/issn.2176-9419.v16ispep7-10

\title{
Apresentação \\ Estudos gramaticais do português: caminhos abertos pelas investigaçóes de Charlotte Galves
}

A revista Filologia e Linguistica Portuguesa apresenta, neste número, um conjunto de trabalhos originados em pesquisas orientadas por Charlotte Marie Chambelland Galves. Um dos nomes mais amplamente reconhecidos entre os estudiosos da língua portuguesa na atualidade, Charlotte Galves construiu uma trajetória que se confunde com o próprio estabelecimento da linguística histórica no Brasil - como mostram Anthony Kroch e Mary Azaiwa Kato no criterioso relato biográfico que abre este volume - e é hoje referência nacional e internacional nos estudos em linguística teórica, diacrônica e de corpus.

Entretanto, há uma faceta menos amplamente conhecida dessa pesquisadora de ponta: Charlotte é também uma professora excepcional, cuja generosidade intelectual faz com que os novos pesquisadores ao mesmo tempo herdem seu afeto pelo objeto investigado e descubram seus próprios caminhos de investigação. É antes de tudo o reconhecimento da importância dessa orientação inicial profundamente formadora e plena de ética científica que motiva o presente tributo, preparado por um pequeno grupo de ex-orientandos de Charlotte. A intenção principal é reunir, em um volume, alguns trabalhos representativos da multiplicidade de perspectivas abertas por sua trajetória de orientaçóes - que completa, neste ano, sua terceira década. Nesses trinta anos, a diversidade de perspectivas da professora em torno das questóes gramaticais do português - sua contribuição teórica, sua investigação sobre a diacronia, sua preocupação com a formação de corpora para estudos futuros - tem se refletido nas diferentes linhas tomadas pelos pesquisadores por ela formados, como poderá ser notado nos trabalhos aqui apresentados.

O primeiro texto, Possessivos de $3^{a}$ pessoa: o português arcaico e o português brasileiro contemporâneo, representa aqui a fase inicial dos trabalhos de orientação de Charlotte no âmbito da diacronia do Português. No texto, Maria Aparecida Torres Morais e Ilza Ribeiro descrevem estratégias possessivas de $3^{\mathrm{a}}$ pessoa, com ênfase nas variação seu e dele, numa perspectiva comparativa entre o português 
arcaico (PA) e o português brasileiro contemporâneo (PB). Com base em Müller $(1997,2003)$ e Menuzzi (1999, 2003a, b), assume-se a tese da especialização de formas: seu tornou-se altamente desfavorecido, na variedade informal do PB, com antecedente referencial de $3^{\mathrm{a}}$ pessoa, sendo tal espaço ocupado pela forma dele. Tal variação é discutida a partir da noção de c-comando aliada ao fato de seu não expressar morfossintaticamente os traços de número (e gênero) do possuidor.

O segundo texto apresenta um aspecto fundamental da pesquisa de Charlotte a partir dos finais da década de 1990: a linguística de corpus. No artigo $O$ corpus Tycho Brahe: contribuiçôes para as Humanidades Digitais no Brasil, Maria Clara Paixão de Sousa apresenta uma reflexão sobre as transformações produzidas pelo tratamento computacional na tradição do trabalho filológico e linguístico com os textos. Tal reflexão é construída com base na análise detalhada das diferentes combinações de procedimentos filológicos, linguísticos e computacionais envolvidos na construção da tecnologia de codificação de textos do Corpus Anotado do Português Histórico Tycho Brahe e na discussão das implicações metodológicas desses procedimentos. No artigo, a autora ainda traz à baila a discussão sobre os desafios e perspectivas que se abrem do trabalho em ambiente digital no campo da filologia e da linguística histórica. Aos trabalhos realizados com base no Corpus Tycho Brahe citados nesse artigo, podem se acrescentar, agora, o grupo seguinte das contribuiçóes neste volume, fundados nos dados históricos longamente reunidos por Charlotte no Corpus.

Inaugurando esse grupo, no artigo intitulado Clíticos e negação em português: elementos para uma descrição gramatical, Cristiane Namiuti e Carlos Mioto discorrem sobre a negação sentencial e sua relação com os clíticos pronominais em língua portuguesa, buscando explicar as diferenças sintáticas entre ambos, com base na natureza da posição pré-verbal e nas possibilidades de alçamento do pronome clítico na história do português. Os autores propóem que o português europeu (PE) e português brasileiro (PB) atuais diferem nos seguintes termos: no $\mathrm{PB}$ um pronome clítico está associado ao verbo lexical; no $\mathrm{PE}$ a um núcleo funcional da flexão verbal.

No artigo A posição e a colocação de clíticos em predicados complexos: o português brasileiro visto a partir de duas vertentes, Aroldo Andrade e Zenaide Carneiro identificam dois tipos de construçóes: perífrases infinitivas e tempos compostos, com base em um corpus constituído por cartas dos séculos XIX e XX, classificadas quanto à escolaridade de seus remetentes. A descrição das mudanças na posição e colocação de pronomes clíticos permitem aos autores testar a hipótese veiculada na literatura corrente de que o português brasileiro é formado por duas vertentes - a norma culta e a norma vernacular ou popular. 
Em $O$ efeito V2 na história do espanhol e português europeus, Carlos Felipe Pinto e André Antonelli discutem a perda do efeito V2 na história do português e sua relação com aspectos sócio-históricos das duas línguas, tendo como hipótese inicial a influência linguística do espanhol como causa da perda do efeito V2 no português. Nesse artigo, os autores apresentam os argumentos que os levam a analisar o espanhol antigo e o português antigo e clássico como línguas V2 e as possíveis causas das mudanças linguísticas sofridas pelo português, como, por exemplo, o contato com as línguas da Península Ibérica.

Já no artigo Diacronia e sujeito nulo no português brasileiro: um estudo comparativo, Aline Gravina, com base na análise de corpora diacrônico do português brasileiro e do português europeu, descreve, comparativamente, o comportamento do sujeito nulo na diacronia dessas duas variedades de português. Os resultados alcançados nesse estudo mostram que: (i) nos dados de PB, com o decorrer do tempo, houve um decréscimo no uso de sujeito nulo e, ao mesmo tempo, um aumento de casos de preenchimento do sujeito através da estratégia Sujeito Lexical Anáforico; (ii) nos dados do PE, o uso de sujeito nulo permaneceu com alta frequência em todos os períodos e ambientes sintáticos analisados; e (iii) a realização do sujeito nulo com primeira pessoa apresentou um comportamento diferenciado do sujeito nulo de terceira pessoa nos dados do PB, o que reforça a hipótese de o PB ser, sincronicamente, uma língua de sujeito nulo parcial.

Para além do trabalho mais especificamente dedicado aos aspectos sintáticos da diacronia, as pesquisas históricas e teóricas de Charlotte são marcadas, também, pelo interesse em aspectos da interface entre a sintaxe e a fonologia. O próximo trabalho neste volume é representativo dessa importante vertente: em Sentenças VOS em português europeu: movimento-p e estrutura entoacional, Flaviane Fernandes-Svartman analisa comparativamente as estruturas sintáticas e entoacionais associadas às sentenças na ordem sujeito-verbo-objeto (SVO neutras) e verbo-objeto-sujeito (VOS com foco informacional no sujeito) em português europeu (PE), com a hipótese de que a prosódia codifica a estrutura sintática associada a esses dois tipos de sentenças de maneiras distintas. A hipótese da autora é confirmada na medida em que os resultados alcançados por ela revelam que a estrutura entoacional das sentenças VOS apresenta mais acentos tonais que a estrutura entoacional das sentenças SVO e que, no caso das primeiras, há ainda um acento tonal específico, $\mathrm{L}^{*}+\mathrm{H}$, associado ao objeto movido da margem direita da sentença, conforme a derivaçâo sintática, via movimento-p (Zubizarreta, 1998), proposta no referido trabalho.

Finalmente, por sobre o trabalho com corpora e a sintaxe diacrônica, e além da vertente da interface sintaxe-fonologia, a trajetória de pesquisas de Charlotte esteve sempre fundada em uma reflexão teórica muito aprofundada. O último texto deste volume faz parte desse caudal mais abstrato das orientaçóes da professora. 
No texto O Axioma da Correspondência Linear e a Estrutura Sintagmática Nua: um levantamento de propostas de compatibilização, Pablo Faria tem como objetivo principal propor uma solução alternativa para a questão da compatibilização entre as propostas de Kayne (1994), e Chomsky (1995 a). O autor argumenta que a maioria das soluçóes apresentadas na literatura são insatisfatórias de uma perspectiva minimalista. Uma solução adequada passa por uma reconcepção da sintaxe, em particular, da operaçáo fundamental para construçáo de estrutura, Merge, de modo que se produza (e não se perca) assimetria desde o início da derivação.

Esperamos que os artigos aqui reunidos reflitam em parte a diversidade de perspectivas e a profundidade das análises propiciadas pelo trabalho orientador de Charlotte Galves. As investigaçôes assim originadas prosseguem, hoje, em importantes centros universitários do Brasil, na figura dos pesquisadores por ela formados - amplitude materializada, neste volume, pela participação de pesquisadores atualmente em atuação na Universidade Federal da Bahia, na Universidade Estadual de Feira de Santana, na Universidade Estadual do Sudoeste da Bahia, na Universidade Federal de Santa Catarina e na Universidade Federal da Fronteira Sul-além da Universidade de São Paulo, que muito honradamente hospeda o tributo. Como ex-alunos, nesses e em outros pontos do país, esperamos conseguir disseminar entre novos pesquisadores a dedicação generosa de Charlotte à investigação e à reflexão que, acreditamos, é uma fundação essencial para o trabalho científico de qualidade.

Para finalizar essa breve apresentação, retomaremos a observação que deu impulso à organização deste volume: todos nós passamos pela experiência de encontrar, nos itens fundamentais da bibliografia de nossas teses e dissertaçóes, a seguinte afirmação: “... nada disso seria possivel sem a inestimável ajuda de Charlotte Galves" - e é por compartilharmos essa experiência que sentimos ser chegado o momento para um tributo a essa pesquisadora cuja contribuição para os estudos linguísticos do português é cada dia mais amplamente reconhecida.

São Paulo, dezembro de 2014.

Carlos Felipe Pinto

(Universidade Federal da Bahia)

Flaviane Fernandes-Svartman

(Universidade de São Paulo)

Maria Aparecida Torres Morais

(Universidade de São Paulo)

Maria Clara Paixão de Sousa

(Universidade de Sáo Paulo) 